\title{
The Electrical Conductivity as an Index of Air Pollution in the Atmosphere
}

\author{
Nagaraja Kamsali ${ }^{1}$, B.S.N. Prasad ${ }^{2}$ and Jayati Datta ${ }^{3}$ \\ ${ }^{1}$ Department of Physics, Bangalore University, Bangalore \\ 2 University of Mysore, Mysore \\ ${ }^{3}$ Indian Space Research Organization, Bangalore \\ India
}

\section{Introduction}

Air is never perfectly clean. Many natural sources of air pollution have always existed. Ash from volcanic eruptions, salt particles from breaking waves, pollen and spores released by plants, smoke from forest and brushfires, and windblown dust are all examples of natural air pollution. Human activities, particularly since the industrial revolution, have added to the frequency and intensity of some of these natural pollutants.

Air pollution has considerable effects on many aspects of our environment: visually aesthetic resources, vegetation, animas, soils, water quality, natural and artificial structures, and human health. The effect of air pollution on vegetation include damage to leaf tissue, needles, or fruit, reduction in growth rates or suppression of growth, increased susceptibility to a variety of diseases, pests, and adverse weather. Air pollution can affect human health in several ways. The effects on an individual depend on the dose or concentration of exposure and other factors, including individual susceptibility. Some of the primary effects of air pollutants include toxic poisoning, causing cancer, birth defects, eye irritation and irritation of the respiratory system, viral infections causing pneumonia and bronchitis, heart diseases, chronic diseases, etc. The consequences of air pollution reach beyond health and agriculture, and they influence the weather as well. There is strong evidence that increased atmospheric contamination reduces visibility, modifies electrical conductivity, alters precipitation, and changes the radiation balance.

The very presence of a city affects the local climate, and as the city grows, so does its climate changes. Now-a-days, cities are warmer than the surrounding areas. The temperature increase is a result of the enhanced production of heat energy, may be the heat emitted from the burning of fossil fuels and other industrial, commercial, and residential sources, and the decreased rate of heat loss since the dust in the urban air traps and reflects back into the city as long wave radiation. In addition, particulates in the atmosphere over a city are often at least 10 times more abundant than in rural areas. Although the particulates tend to reduce incoming solar radiation by up to $30 \%$ and thus cool the city, this cooling effect of particulates is small in relation to the effect of processes that produce heat in the city.

Particulate matter encompasses the small particles of solid or liquid substances that are released into the atmosphere by many activities and are referred to as aerosols. Modern farming adds considerable amounts of particulate matter to the atmosphere, as do 
desertification and volcanic eruptions. Nearly all industrial processes, as well as the burning of fossil fuels, release particles into the atmosphere. Much particulate matter is easily visible as smoke, soot, and dust. Emission of aerosols to the atmosphere has increased significantly since the industrial revolution began. An aerosol is a particle with a diameter less than $10 \mu \mathrm{m}$. Because the effects of collisions with air molecules dominate over gravity, the smaller aerosol particles tend to remain in the atmosphere for a long time. Bigger particles of diameter greater than $10 \mu \mathrm{m}$ drop out of the atmosphere faster because of gravity. Recent research has indicated that aerosols emitted from coal (sulfates) may contribute to global cooling because sulfates act as seeding for clouds, the aerosol particles provide surfaces for water to condense, forming clouds that reflect a significant amount of sunlight directly. The net cooling owing to sulfate aerosols may offset partially the global warming expected from the anthropogenic greenhouse effect.

The concern that man's activity in a world of rapidly growing population may lead to inadvertent modification of the climate on a local basis and even on a global scale, has led to the establishment of a worldwide network of air quality monitoring stations. An important parameter to be monitored is the particulate load of the atmosphere, which may have a direct impact on the climate change. Recently, atmospheric electric scientists have renewed their interest in the possibility of using atmospheric electrical parameters as indices of air pollution trends, despite the complexity of the relationship involved. Comparing fair weather conductivity recorded on the Carnegie expedition during 1967 revealed a decreasing trend of conductivity, which has dropped at least $30 \%$ in the North Atlantic. This decreasing trend in conductivity is attributed to a significant rise in the aerosol pollution over the Northern hemisphere.

An attempt has been made (Nagaraja Kamsali et al., 2009) to infer pollution trend from atmospheric electrical conductivity on a regional basis. There seems to be sufficient evidence that atmospheric electrical conductivity, properly deduced and analyzed, with due consideration of the local meteorology and air pollution climatology, may serve as a sensitive and practical tool, capable of documenting aerosol air pollution trends, especially secular changes, in largely populated urban area. Considering the relative simplicity and reliability of the electrical conductivity measurement, which is well suited for continuous and automatic recording, its inclusion in the measurement program of the regional air pollution may be preferred.

\subsection{Radioactivity of the Earth's atmosphere}

The rocks and soil in the solid Earth contain radioactive elements, $238 \mathrm{U}$ and ${ }^{232} \mathrm{Th}$ in the form of minerals Uranite and Monozite; their concentrations vary from region to region. Decay of these elements release $\alpha, \beta$ and $\gamma$ radiations along with daughter products, which themselves may or may not be radioactive. Some of the daughter elements are gases such as radon and thoron. These gases get either released into the atmosphere or trapped within the rock soil, depending on the permeability of the surrounding material. The radioactive gases released from the soil get mixed with the atmospheric air and contribute to ionization during their decay. The concentration of these gases varies from place to place, and with altitude at any given place. The distribution of these gases with altitude depends on the atmospheric stability. The decay products of these gases are mostly radioactive elements, and they also contribute to the ionization of air.

The origin of radon and thoron in the Earth's crust stems directly from the radium isotopes and their decay products distributed in minute quantities in the ground within few meters 
from the Earth's surface. Once the isotopes of the gas are produced they migrate to a significant distance from the site of generation, even during their brief half-lives. A fraction of the radon gas generated in soil near the Earth's surface enters into the atmosphere before undergoing into the radioactive decay. The amount of radon gas that escapes depends on the amount of ${ }^{226} \mathrm{Ra}$ and ${ }^{232} \mathrm{Th}$ in the ground, the type of soil, porosity, dampness and meteorological conditions. The amounts of ${ }^{222} \mathrm{Rn}$ (radon), ${ }^{220} \mathrm{Rn}$ (thoron) and ${ }^{219} \mathrm{Rn}$ (action) in the atmosphere depend primarily on the concentration of $238 \mathrm{U},{ }^{232} \mathrm{Th}$ and $235 \mathrm{U}$. The relative abundances of the isotopes in natural uranium by weight are $238 \mathrm{U}-99.28 \%, 235 \mathrm{U}-0.71 \%$ and ${ }^{234} \mathrm{U}-0.0054 \%$. On the other hand, ${ }^{232} \mathrm{Th}$ is even more abundant than ${ }^{238} \mathrm{U}$ in the Earth's crust.

At present, twenty isotopes of radon are known. ${ }^{222} \mathrm{Rn}$, from radium, has a halflife of 3.823 days; ${ }^{220} \mathrm{Rn}$ emanating naturally from thorium and called thoron has a halflife of $55.6 \mathrm{~s} .{ }^{219} \mathrm{Rn}$ emanating from actinium and called actinon has a halflife of 3.96s. It is estimated that every square mile of soil to a depth of 6 inches contains about $1 \mathrm{~g}$ of radium, which releases radon in tiny amounts into the atmosphere.

\subsection{Radon entry into the atmosphere}

For a radon atom to escape from the mineral grain into the pore space, the decay must occur within the recoil distance of the grain surface. The recoil range for ${ }^{222} \mathrm{Rn}$ is $20-70 \mathrm{~nm}$ in common minerals, $100 \mathrm{~nm}$ in water, and $63 \mu \mathrm{m}$ in air. Radon atoms entering the pore space are then transported by diffusion and advection through this space until they in turn decay or are gets released into the atmosphere. The escape of radon atoms from soil grains into the pore space is called radon emanation. The transportation of radon atoms from pore space by diffusion and advection through the space and gets released into the atmosphere is called radon exhalation. The amount of radon released per unit surface area per unit time is called radon exhalation rate. The rate of radon exhalation from soil depends on geophysical parameters such as geology of the region, soil porosity, soil texture, humidity and temperature of the soil, and also on meteorological parameters such as temperature, humidity, pressure etc. The influence of environmental parameters on the exhalation rate of ${ }^{222} \mathrm{Rn}$ from soil is not clearly understood. When the soil is frozen or covered with snow, the exhalation rate is reduced because diffusion processes are slowed down. It was observed by George (1980) that, the exhalation rate was linearly correlated with outdoor temperature. However, Arabzedegan et al., (1982) observed that the meteorological parameters had no significant influence on the value of ${ }^{222} \mathrm{Rn}$ exhalation rate. Raghavayya et al., (1982) have found that soil moisture had a strong influence on the ${ }^{222} \mathrm{Rn}$ exhalation rate. ${ }^{222} \mathrm{Rn}$ exhaled from the surface soil reaches the atmosphere and further decays to a series of radionuclides which are heavy metal radionuclides that attach to other atmospheric components to form aerosol particles.

\subsection{Ionization in the atmosphere}

Cosmic radiation is the primary source of ions over the oceans and above a couple of kilometers over the land (Hoppel et al., 1986). In the lower atmosphere, ions are predominantly produced by radiation emitted from radioactive materials in the soil, in building materials, and in the air (radon and its daughter products). The $\alpha$ and $\beta$ particles and the $\gamma$ rays from ${ }^{222} \mathrm{Rn},{ }^{220} \mathrm{Rn}$ and their decay products give up their energy by producing ions and raising atoms and molecules to excited states. An $\alpha$ particle from the decay of ${ }^{222} \mathrm{Rn}$ 
atom $(5.49 \mathrm{MeV})$ will produce about 150,000 ion pairs with the expenditure of about $34 \mathrm{eV}$ per ion-pair along its trajectory through the surrounding air in the atmosphere (Israel, 1970). Cosmic radiation contributes about $10 \%$ to the ionization at ground level. However, at higher altitudes, the partitioning shifts drastically both because the radiation from the soil and airborne materials decreases whereas the intensity of the cosmic radiation increases.

The radioactive gases $\left({ }^{222} \mathrm{Rn}\right.$ and $\left.{ }^{220} \mathrm{Rn}\right)$ can diffuse from the ground into the atmosphere and contribute to the volume ionization. The concentration of these gases and the rate of ionization in the atmosphere depend upon the amount of uranium and thorium in the ground, and the temperature, dampness and porosity of the soil. Radon emanated from the Earths crust reaches the atmosphere and further decays to a series of short lived radionuclides namely, polonium $(218 \mathrm{Po})$, lead $(214 \mathrm{~Pb})$ and bismuth $\left({ }^{214} \mathrm{Bi}\right)$. Radiation from radioactive gases exhaled from the ground and their daughter products causes ionization in the atmosphere. Radon is one of the relatively longer-lived gases. The principal decay modes and half-lives of ${ }^{222} \mathrm{Rn}$ and its short-lived daughters in order are ${ }^{222} \mathrm{Rn}-\alpha, 3.82$ days; ${ }^{218 \mathrm{Po}}-\alpha, 3.05 \mathrm{~min} ;{ }^{214} \mathrm{~Pb}-\beta, 26.8 \mathrm{~min}$; ${ }^{214} \mathrm{Bi}-\beta, 19.7 \mathrm{~min}$; and ${ }^{214} \mathrm{Po}-\alpha, 2 \times 10^{-4} \mathrm{~s}$. The radiations $\alpha, \beta$ and $\gamma$ released during the decay of radon and its progeny cause ionization, and hence these are important in the study of atmospheric electricity. Ionization due to radioactive gases in the air is even more variable and depends not only on the amount exhaled from ground but also on atmospheric dispersion. Direct measurements of ionization due to radioactive gases in the atmosphere are difficult and have not generally been satisfactory. Estimation of ionization rate is therefore based on measurements of radioactive products in the air at that level, while the ionization due to cosmic radiation is almost constant with time. On cool nights with nocturnal temperature inversions the radioactive gases can be trapped in a concentrated layer close to the ground, whereas during unstable convective periods, the gases can be dispersed over an altitude of several kilometers. But during daytime due to convective processes, these gases disperse to higher altitudes. Because of this, the height distribution of radon in the atmosphere has also been used to determine the turbulent diffusion coefficient (Hoppel et al., 1986).

\subsection{Influence of meteorological parameters on lonization}

In general, the ionization increases rapidly with height but shows certain changes in the troposphere and stratosphere that appear to be associated with the existence of aerosol layers (Israel, 1971). However, in the lowest region of the atmosphere the rate of ionization greatly depends upon the different meteorological parameters. The ionization rate near the Earth's surface is markedly influenced by variations in meteorological parameters such as wind and precipitation, in addition to the particles and air mass in the atmosphere. The wind speed which is produced under the influence of pressure gradient and Coriolis force is highly variable in time and space. It is an important factor in the transportation of atmospheric nuclei and ions in the atmosphere. It shows diurnal as well as seasonal variations. Its magnitude and direction vary with height and hence the density of ionization in the atmosphere is very much influenced by the wind. However, the precipitation is another important meteorological parameter which has a profound influence on the ion content of the atmosphere. It washes out both positive and negative ions, leaving the air fairly low in ion content. The degree of washout depends on the spectrum of the rain and its duration. Addition to this, the air mass also influences the ionization. The qualities of an air mass depend upon the region over which it stagnates for a sufficiently long time and 
acquires the characteristics of the environment. Air mass that lies over the densely populated areas and cities will be weak in the ion content because of the large quantity of particulate matter that goes into it from the city environment. Air mass that lies over the rural surroundings is mostly free from such particulate matter and hence it is rich in ion content. Thus the quality of an air mass influences the ion content and consequently columnar resistance of the local generator. Another major parameter is the suspended particles in the atmosphere. These particles always exist in the atmosphere but the number varies with the atmospheric conditions. The visibility of the atmosphere is a good indicator of the particle content in the atmosphere. It enhances the formation of fog and cloud in the atmosphere under certain favourable conditions. They promote attachment of ions to particles and reduce their mobility.

\subsection{Particulate matter in the atmosphere}

Particulate matter encompasses the small particles of solid or liquid substances that are released into the atmosphere by many activities and are referred to as aerosols. Modern farming adds considerable amounts of particulate matter to the atmosphere, as do desertification and volcanic eruptions. Nearly all industrial processes, as well as the burning of fossil fuels, release particles into the atmosphere. Much particulate matter is easily visible as smoke, soot, and dust. Emission of aerosols to the atmosphere has increased significantly since the industrial revolution began. An aerosol is a particle with a diameter less than $10 \mu \mathrm{m}$. Because the effects of collisions with air molecules dominate over gravity, the smaller aerosol particles tend to remain in the atmosphere for a long time. Bigger particles of diameter greater than $10 \mu \mathrm{m}$ drop out of the atmosphere faster because of gravity. The aerosols emitted from coal (sulfates) may contribute to global cooling because sulfates act as seeding for clouds, the aerosol particles provide surfaces for water to condense on, forming clouds that reflect a significant amount of sunlight directly. The net cooling owing to sulfate aerosols may offset much of the global warming expected from the anthropogenic greenhouse effect.

\subsection{Air pollution}

Air is never perfectly clean. Many natural sources of air pollution have always existed. Ash from volcanic eruptions, salt particles from breaking waves, pollen and spores released by plants, smoke from forest and brushfires, and windblown dust are all examples of natural air pollution. Ever since people have been on earth, however, they have added to the frequency and intensity of some of these natural pollutants. As the faster moving fluid medium in the environment, the atmosphere has always been one of the most convenient places to dispose of unwanted materials. Ever since fire was first used by people, the atmosphere has been a sink for waste disposal. As long as a chemical is transported away or degraded relatively rapidly, there is no pollution problem. Chemical pollutants can be thought of as compounds that are in the wrong place or in the wrong concentrations at the wrong time. Pollutants that enter the atmosphere through natural or artificial emissions may be broken down or degraded not only within the atmosphere but also by natural processes in the hydrologic and geochemical cycles; pollutants that leave the atmosphere may become pollutants of water and of geological cycles.

Air pollution has considerable effects on many aspects of our environment: visually aesthetic resources, vegetation, animals, soils, water quality, natural and artificial structures, 
and human health. The effect of air pollution on vegetation include damage to leaf tissue, needles, or fruit, reduction in growth rates or suppression of growth, increased susceptibility to a variety of diseases, pests, and adverse weather. Air pollution can affect human health in several ways. The effects on an individual depend on the dose or concentration of exposure and other factors, including individual susceptibility. Some of the primary effects of air pollutants include toxic poisoning, causing cancer, birth defects, eye irritation and irritation of the respiratory system, viral infections, causing pneumonia and bronchitis, heart diseases, chronic diseases, etc. Wherever there are many sources emitting air pollutants over a wide area there is a potential for the development of smog. Whether air pollution develops depends on the topography and on weather conditions, because these factors determine the rate at which pollutants are transported away from their sores and converted to harmless compounds in the air. When the rate of production exceeds the rate of degradation and of transport, dangerous conditions may develop. Meteorological conditions can determine the fate of air pollution. Air pollution and meteorology are linked in two ways. One concerns the influence that weather conditions have on the dilution and dispersal of air pollutants. The second connection is the reverse and deals with the effect that air pollution has on weather and climate. Air pollution is a continuing threat to our health and welfare. The cleanliness of air, therefore, should certainly be as important to us as the cleanliness of food and water.

The concern that man's activity in a world of rapidly growing population may lead to inadvertent modification of the climate, on a local basis and even on a global scale, has led to the establishment of a worldwide network of air quality monitoring stations. An important parameter to be monitored is the particulate load of the atmosphere, which may have a direct impact on the climate change. Recently, atmospheric electric scientists have renewed their interest in the possibility of using atmospheric electrical parameters as indices of air pollution trends, despite the complexity of the relationship involved. Comparing fair weather conductivity recorded on the Carnegie expedition during 1967 revealed a decreasing trend of conductivity, which has dropped at least $30 \%$ in the North Atlantic. This decreasing trend in conductivity is attributed to a significant rise in the aerosol pollution over the Northern hemisphere. An attempt to infer pollution trend from atmospheric electrical conductivity on a regional basis, due to extensive urbanization has been made. There seems to be sufficient evidence that atmospheric electrical conductivity, properly reduced and analyzed, with due consideration of the local meteorology and air pollution climatology, may serve as a sensitive and practical tool, capable of documenting aerosol air pollution trends, especially secular changes, in largely populated areas.

\subsection{Electrical nature of the Earth's atmosphere}

The planetary boundary layer is that region of the lower atmosphere in which the influences of the earth's surface are directly felt. The primary influences of the surface are drag, heating (or cooling), and evaporation (or condensation). These processes cause vertical fluxes of momentum, sensible heat, and moisture, which penetrate into the lower atmosphere to a finite height. These fluxes, in turn, generate turbulence, ultimately controlling the mean profiles of wind speed, temperature, and water vapour in the planetary boundary layer.

Atmospheric electrical conductivity, ion mobility and small ion number density, etc. are important parameters for understanding the electrical nature of the atmosphere. The small ions consisting of aggregates of few molecules determine the electrical conductivity over the 
region (Israel, 1970). The number densities of these ions are controlled by ionizing mechanisms for the production of ions and electrons, and the loss processes for these charged species. The electrical conductivity of the air in an aerosol free atmosphere is mainly due to small ions. However, in a polluted atmosphere these ions soon get attached to the aerosol particles and form the intermediate and large ions. Since the mobility of small ions is at least two orders of magnitude more than that of large ions, the small ions are still considered to be, if not the only, the main contributors to the local electrical conductivity (Dhanorkar and Kamra, 1997). Since the presence of aerosol particles depletes the small ions, the electrical conductivity and aerosol concentration are generally considered to have an inverse relationship in the atmosphere and the electrical conductivity has been often proposed to act as an index of air pollution. The decrease in electrical conductivity with an increase in air pollution has been reported under different meteorological conditions such as in continental air (Misaki, 1964; Mani and Huddar, 1972), near coastlines (Misaki and Takeuti, 1970; Morita et al., 1972; Kamra and Deshpande, 1995), in marine air (Cobb and Wells, 1970), at the level of inversion (Rosen and Hofmann, 1981) and during volcanic eruption (Srinivas et al., 2001).

The electrical conductivity of the air is mainly due to the presence of highly mobile small ions produced in the atmosphere by cosmic rays and local radioactive sources (Retalis et al., 1991). A balance is maintained since the small ions are being removed from the atmosphere at the same rate that they are being produced. They are removed by recombination with oppositely charged small ions and by attachment to larger aerosol particles. These recombination and attachment processes thus determine the life times of small ions in the atmosphere and secondarily of the conductivity, since its value is formed predominantly by the small ion concentration in the air. Ion lifetimes near earth's surface vary from $20 \mathrm{sec}$ in highly polluted air to $300 \mathrm{sec}$ in very clean air (Cobb, 1973).

\subsection{The electrical conductivity of the atmosphere}

The atmospheric electrical conductivity depends on the existence of positive and negative ions. If a small potential is applied to two electrodes in an ionized gas, a week current flow is induced by the ions which flow in opposite directions to the electrodes where they deliver their charge. The current density (per unit cross section) is defined as the amount of electric charge which flows per unit time through a unit surface area perpendicular to the direction of flow. The current density is composed of two terms corresponding to the respective ion flow, and is given by the relation $i=e\left(n^{+} \mu^{+}+n^{-} \mu^{-}\right) E=\sigma E$, where $\mu^{+}$and $\mu^{-}$are the mobilities and $\mathrm{n}^{+}$and $\mathrm{n}^{-}$are the ion concentrations of positive and negative polarity, and e is the electronic charge. The resulting conductivity can be expressed in terms of the number densities and mobilities of the individual species as $\sigma=e\left(n^{+} \mu^{+}+n^{-} \mu^{-}\right)$. For several types of ions of different mobility are present, the above expression become $\sigma=e \sum_{i=1}^{n}\left(n_{i}^{+} \mu_{i}^{+}+n_{i}^{-} \mu_{i}^{-}\right)$.

Near to the Earth's surface, electrical conductivity is not constant with time. Observations over long periods at various sites have shown that atmospheric conductivity has well defined diurnal and seasonal variations during fair weather periods. The exact nature of variation differs with stations, the mean values and amplitude being different. For a given 
station, the pattern of variation of conductivity at the surface normally remains more or less a constant during a year. The average behaviour at each station may therefore be characteristic of the 'atmospheric electric climate' of that station. But some similarities are seen in the diurnal behaviour of conductivity at most stations. For instance, conductivity is higher at night than during the day. This is typical for continental stations and makes it probable that, apart from all local and other influences, a more general factor which causes this general tendency in the diurnal variation must exist. This variation is possibly a reflection of the general rhythm of the atmosphere, since nights are usually calmer, with low winds and hardly any convective motion, and therefore conducive for accumulation of radon and other radioactive species near the surface. A sharp fall associated with sunrise is seen at many stations. This is believed to be due to an increase in the aerosol concentration due to onset of circulation and human activity. In marine air, the mean conductivity is slightly higher than that over land but the diurnal amplitude is very low. The average value on land is about $1.8 \times 10^{-14} \Omega^{-1} \mathrm{~m}^{-1}$ while over the ocean it is about $2.8 \times 10^{-14} \Omega^{-1} \mathrm{~m}^{-1}$ (Chalmers, 1967). And unlike over land, conductivity over ocean is minimum in the late afternoon or early evening hours, and remains low during night. It rises to a peak in the forenoon and is followed by a gradual decline. This is almost a mirror image of the pattern seen over continental stations. Further, while the positive conductivity displays a clear variation in the manner described, the variation in the negative conductivity has very low amplitude and is just discernible. The ratio of polar conductivities thus exhibits a clear pattern over ocean. From the life time it is well known that, the mobility of large or intermediate ions are a few orders of magnitude smaller than those of small ions. So, their contribution to the polar conductivity is relatively smaller than that of the small ions. Small ions of opposite polarity recombine and cause a decrease in the small ion concentration and consequently a reduction in the conductivity of air. There exist a close correlation between the concentration of small ions and polar conductivity near the surface of Earth. In the presence of aerosol particles losses in the small ion concentration are caused not only due to the ion-ion recombination process, but also due to attachment of small ions to the aerosol particles. Attachment of small ions to the aerosol particles makes them almost immobile and causes a further decrease in conductivity of the atmosphere. This develops inverse relationship between the aerosol concentration and the electrical conductivity (Cobb and Wells, 1970). Mani and Huddar (1972) observed the decrease in conductivity presumably caused due to increase in dust particle content at Pune, India over a period of 20 years. Hogan et al., (1973) pointed out that the conductivity inversely follows the product of aerosol size and number density better than the number density alone. Similar type of results was obtained by Srinivas et al., (2001) and they concluded that the conductivity of the atmosphere depends on the number density of aerosols rather than their concentration alone. Cobb (1973) suggested that this product is really close to what is meant by pollution. Due to this inverse relationship between the electrical conductivity and the pollution, the electrical conductivity has been proposed to act as a pollution index.

\subsection{Need for theoretical estimation of electrical conductivity of the atmosphere}

Measurements of atmospheric electrical conductivity are in general difficult to interpret because of large variety of influencing factors. Therefore, a thorough theoretical and experimental analysis is necessary in order to conduct research in atmospheric electricity. In the atmospheric surface layer, particularly the lowest few meters above the ground, large 
number of factors will dominate, for example, radioactive emanation from the ground; porosity, dampness and temperature of the soil; aerosol concentration; atmospheric electric field and mobility of small ions. The electrical conductivity is very sensitive to the presence of aerosols. Thus, the aerosol loading has a bearing on the conductivity of the atmosphere. The aerosols reduce the conductivity of the atmosphere by (i) converting the highly mobile small ions into less mobile aerosol ions through ion - aerosol attachment and (ii) neutralizing the small ions through the aerosol ion - small ion recombination. Another process that makes the ion-aerosol attachment rate faster is the charged aerosol - aerosol recombination. In the present communication ion - aerosol interactions are taken into account to develop a model for the electrical conductivity of the atmosphere. It is validated by comparing the computed values of conductivity with the experimental values.

Several model studies on the electrical conductivity of the atmosphere of higher altitude are available (Datta et al., 1987; Prasad et al., 1991; Srinivas and Prasad, 1993, 1996). Most of the model studies have considered the loss of small ions as solely due to a) ion - ion recombination b) ion - attachment to aerosols. The other two types of loss of small ions arise from a) the recombination of molecular ions with oppositely charged aerosol and b) charged aerosol - aerosol recombination, and hence further deplete the small ions. Obviously, addition of these two terms results in more realistic values (Srinivas et al., 2001). The equilibrium density of small ions is governed by the equations of continuity for the production and loss of these ions, where the gain and loss due to transport are negligible. The effective recombination of small ions is altered in the presence of aerosols, since these aerosols interact with the ions through various attachment and recombination processes. The attachment of small ions to neutral aerosols produce charged aerosols referred to as 'large ions', which are less mobile than the smaller molecular ions. The subsequent recombination of charged aerosols with ions as well as oppositely charged aerosols would result in the depletion of small ion concentration more rapidly than in the absence of aerosols. Therefore, the formation of less mobile aerosol ions and the reduction of more mobile molecular ions alter the electrical conductivity of the atmosphere. Thus, the pollution due to aerosols/dust in the atmosphere can considerably reduce the atmospheric conductivity. Hence, the atmospheric pollution level can be monitored through electrical conductivity measurements and conductivity is used as index of air pollution.

\section{Instrumentation and methodology}

\subsection{Radon concentration in air}

Concentration of radon in air at a height of $1 \mathrm{~m}$ above the surface is measured using the Low Level Radon Detection System. The procedure briefly consists of sampling the air in a collection chamber and exposing a circular metallic disc to the radon inside the collection chamber. A delay of at least 10-min is normally allowed for any thoron, which may be present in the chamber to decay completely. The positively charged ${ }^{218} \mathrm{Po}(\mathrm{RaA})$ atoms created in the chamber get collected on the metallic plate maintained at an optimum negative potential that should be sufficient to force all the RaA atoms onto the plate. The collection is carried out for an optimized period and thereafter the charged plate is removed from the chamber and alpha-counted. The concentration of radon, $R_{n}$, (in $\mathrm{Bq} \mathrm{m}^{-3}$ ) is calculated (Nagaraja et al., 2003a) with the expression: $\mathrm{Rn}=1000 \mathrm{C} /(\mathrm{EFVZ})$ where $\mathrm{C}$ is the total number of counts, $\mathrm{E}$ is the efficiency of alpha counting system, $\mathrm{F}$ is the efficiency of collection of RaA-atoms on the metallic disc and is empirically related to the relative 
humidity $(\mathrm{H})$ by $F=0.9 *[1-\exp (0.039 * H-4.118)], \mathrm{V}$ is the volume of chamber, $\mathrm{Z}$ is the correction factor for build up and decay of radon daughter atoms on the metallic disc during the exposure and counting period.

\subsection{Radon progeny concentration in air}

An air flow meter kept at a height of $1 \mathrm{~m}$ above the surface is used to measure the radon progeny concentration. Air is drawn through a glass fiber filter paper by means of a suction pump at a known flow rate. The radon progeny in air sample are retained on the filter paper. The filter paper is then alpha-counted at any specific delay time. Total activity on the filter paper is measured at three different counting intervals of $2-5,6-20$ and $21-30$ minutes. Activities of polonium $(\mathrm{RaA})$, lead $(\mathrm{RaB})$ and bismuth $(\mathrm{RaC})$ (in $\mathrm{Bq} \mathrm{m}^{-3}$ ) are calculated using the modified equations given by Raghavayya (1998):

$$
\begin{aligned}
R a A & =\frac{+4.249019 \times C_{1}-2.062417 \times C_{2}+1.949949 \times C_{3}}{V \times E} \\
R a B & =\frac{-0.355129 \times C_{1}+0.006232 \times C_{2}+0.240618 \times C_{3}}{V \times E} \\
R a C & =\frac{-0.215175 \times C_{1}+0.371319 \times C_{2}-0.502945 \times C_{3}}{V \times E} \\
R_{d} & =\frac{+0.048445 \times C_{1}-0.019335 \times C_{2}+0.037053 \times C_{3}}{V \times E}
\end{aligned}
$$

where $C_{1}, C_{2}$ and $C_{3}$ are the gross counts during the three counting intervals, $E$ is the efficiency of alpha counting system, $V$ is the sampling rate in liters per minute (LPM), $R_{d}$ is the concentration of radon progeny (in Working Level)

\subsection{Ion - pair production rate due to radioactivity}

The ion-pair production rate due to radon and its progeny is calculated using the expression: $\mathrm{Q}=\varepsilon / \mathrm{I}$ and $\varepsilon=5.49 \times 10^{6} \mathrm{Rn}+6.00 \times 10^{6} \mathrm{RaA}+0.85 \times 10^{6} \mathrm{RaB}+7.69 \times 10^{6} \mathrm{RaC}$ where $\mathrm{Rn}$ is the concentration of radon (in $\mathrm{Bq} \mathrm{m}^{-3}$ ), $\mathrm{RaA}, \mathrm{RaB}$ and $\mathrm{RaC}$ are the concentration of radon progenies i.e., polonium, lead and bismuth (in $\mathrm{Bq}^{-3}$ ), respectively, $\varepsilon$ is the total energy (in $\mathrm{eV}$ ) released by the decay of radon and its progeny, $\mathrm{I}$ is the energy required to produce one ion-pair $=32 \mathrm{eV}, \mathrm{Q}$ is the ion-pair production rate (ion-pairs $\mathrm{cm}^{-3} \mathrm{~s}^{-1}$ ).

\subsection{Aerosol concentration near the earth's surface}

The concentrations of aerosols were measured with an Electrical Aerosol Analyzer in the size range from 3 to $750 \mathrm{~nm}$ diameter. The instrument works on the principle of diffusion charging-mobility analysis of particles. The ambient air is sampled at a rate of 50 litre per minute. The samples is first exposed to a $\mathrm{Kr}-85$ radioactive neutralizer and then passed through a mobility analyzer that contains concentric cylindrical electrodes and a central collector rod. A pre-determined voltage is applied between the electrodes to produce an electric field in the condenser. The charged particles are deflected towards the collector rod by the electric field and the concentration of aerosols is measured in terms of mobility spectrum (Liu and Pui, 1975). A computer is interfaced with analyzer to measure the size distribution. 


\subsection{Electrical conductivity of the atmosphere}

The Gerdien condenser is basically a cylindrical capacitor that collects atmospheric ions and provides air's electrical conductivity, which is shown in Fig. 1 and plate 1. It consists of two coaxial cylinders between which air is allowed to flow. A voltage is applied to one cylinder, known as the driving electrode, with respect to the other. This driving voltage repels ions of one polarity towards the other electrode where ions get collected. It is measured using a sensitive electrometer. For voltages that are sufficiently low, the collector current increases in proportion to the driving voltage. The collector current at these voltages is given by the expression: $\mathrm{I}=\sigma \mathrm{CV} / \varepsilon_{0}$. Gerdien condenser measurements have some sources of errors caused either due to non-fulfillment of some ideal conditions or due to improper adjustment of some important controlling factors such as potential, air flow rate etc and these factors have to be considered in the estimation of conductivities.

In case the humidity is very high, like during fog, it does not directly influence the proper function of the condenser. Apart from this, cobwebs, fragments of feathers, and accumulated dust, may, become conducting in humid air. In such a case the conductivity values increase drastically and reach unrealistic magnitudes. Similar effects can be observed when very small insects enter the inner cylinder. Hence, it is necessary to maintain the area surrounding the condenser free from the insects, cobwebs, dust, leaves etc.

The electric field inside the Gerdien condenser is assumed to be independent of axial distance. This is true only for an infinitely long condenser. For a condenser of finite length, the electric field distribution gets modified at the ends. This is called the 'edge effect'. At the ends of the condenser, some field lines originating at the outer surface of the driving electrode terminate at the collector. The field lines which are straight in the interior and perpendicular to the capacitor electrode are distorted at the edge. Because of this, some ions which are not present in the volume of air being sampled are also pulled in. Thus, the internal field does not end at the capacitor edge, but extends outside the region. Consequently, the ions experience an electric field even before entering the capacitor. Difficulties related to the edge effect can be reduced when the outer electrode is closer to the earth's potential. However, since it is easier to maintain the inner tube at a high level of insulation required for electrometer usage, the accelerating potential is most commonly applied to the outer tube and an electrometer is connected to inner cylinder. The diverging of the electric field around the entrance of the outer electrode may also be avoided with the aid of a grounded entrance cylinder. This and various other modifications suggested to homogenize the field at the capacitor inlet do not remove the field disturbance completely. Moreover, such arrangements introduce another source of error; the losses due to diffusion of ions to devices introduced to remove edge effects. Any such device is, therefore, not introduced in our condenser.

The atmospheric electrical conductivity of both positive and negative polarities is simultaneously measured with two Gerdien condensers housed separately in a single unit as in Fig. 1, locally fabricated at Pune, India. The apparatus consists of two identical cylindrical tubes of $10-\mathrm{cm}$ diameter and $41 \mathrm{~cm}$ length joined by a U-shaped tube. The air is sucked through them with a single fan fixed at the end of U-shaped tube. The flow rate in each tube is about 19 liters per second. The inner co-axial aluminum electrodes in both the tubes are of 1-cm diameter and $20 \mathrm{~cm}$ length, and are fixed well inside the outer electrodes with Teflon insulation. The outer electrodes are shielded from any external electric field by two coaxial cylinders of $11 \mathrm{~cm}$ diameter and $35 \mathrm{~cm}$ length separated from the outer electrodes with Bakelite rings. Opposite but equal potentials of $\pm 35 \mathrm{~V}$ are applied to the 


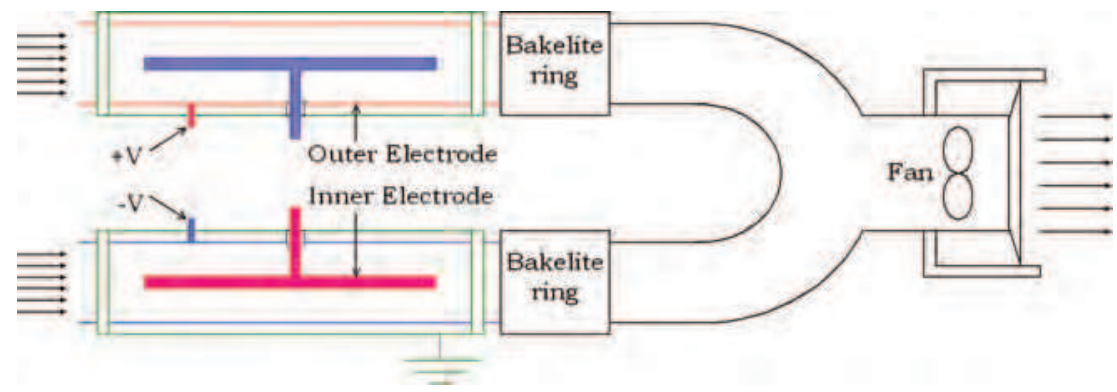

Fig. 1. Schematic representation of the Gerdien Condenser

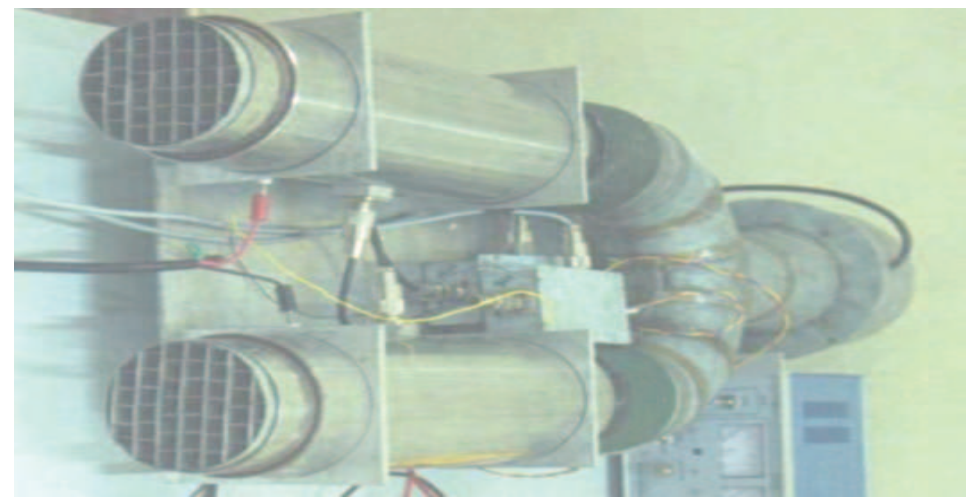

Plate 1. Gerdien Condenser

outer electrodes of the two condensers. The critical mobility of the instrument is greater than $2.93 \times 10^{-4} \mathrm{~m}^{2} \mathrm{~V}^{-1} \mathrm{~s}^{-1}$ (Dhanorkar and Kamra, 1993) and is capable of resolving the values of conductivity as small as $3 \times 10^{-16} \Omega^{-1} \mathrm{~m}^{-1}$ (Dhanorkar and Kamra, 1992). To avoid leakages along the insulators at higher humidity, Teflon is used to insulate all high impedance points in the apparatus because it maintains good insulation even at high humidity. The signals from the two condensers are amplified separately with two electrometer amplifiers AD 549J, and are carried through a separate coaxial cable and then recorded on a data logger card, which has a voltage range of $\pm 15 \mathrm{~V}$ with $10 \mathrm{mV}$ resolutions. Though each sensor is scanned every second, the data logger card records averaged values of each parameter for every one-minute and then stores the values on a computer. Then it is averaged for any desired length of time with the help of an external program. In our case we have averaged this for every hour. The card has the capability of storing data at the maximum of 100 samples per second. In our case we made 60 samples per second and then it was averaged for a minute or for any desired length of time with the help of an external program. The diurnal and / or seasonal variations of radioactivity and the electrical conductivity of the atmosphere, and their dependence on meteorological parameters are presented for a continental station Pune $\left(12 \circ \mathrm{N}, 76^{\circ} \mathrm{E}\right)$, India.

\subsection{Meteorological parameters}

The meteorological parameters such as temperature, pressure, wind speed and wind direction near the surface of the earth are obtained by automatic weather station 
installed near the observatory. Relative humidity is estimated from the wet and dry bulb thermometers.

\section{Simple ion aerosol model for the estimation of electrical conductivity}

There have been no reports on modeling study of the electrical conductivity in the lower part of the troposphere, in particular near the surface. Modeling for this region requires, ionic aerosols, in addition to the molecular ions. Based on this, a Simple Ion-Aerosol Model is proposed and the schematic diagram is shown in Fig. 2. It involves primary ion pair production rate due to surface radioactivity and cosmic rays, the small ion densities $\left(\mathrm{N}_{ \pm}\right)$ and the aerosol number density. For the model prediction of equilibrium ion density and conductivity, it is necessary to use all the four loss processes of ions involved. The various recombination coefficients that enter into the model are: $\alpha_{i}$ due to the loss of oppositely charged small ions, $\alpha_{a}$ due to oppositely charged aerosol ions, $\alpha_{s}$ between small ions and aerosol ions, $\beta$ due to attachment of small ions of similar polarities with aerosols.

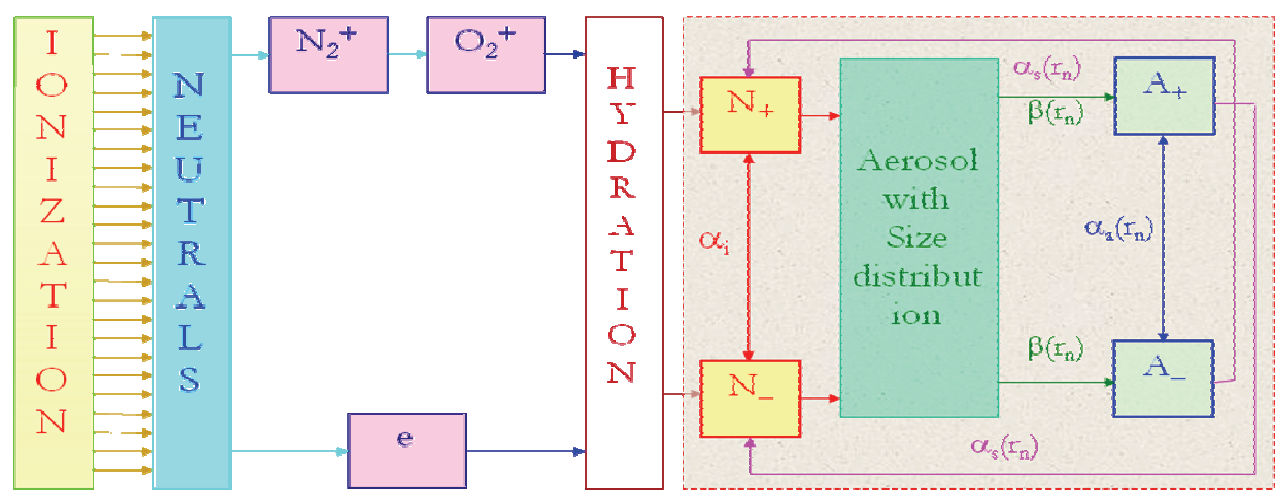

Fig. 2. Schematic representation of ion aerosol model

The temperature, pressure, relative humidity, ionization rate and aerosol number density along with the different attachment/recombination coefficients are the input parameters for the model. With these inputs the electrical conductivity is estimated. However, the model gives the total conductivity and does not make any distinction between positive and negative ion conductivities.

\subsection{Theoretical description of the Model}

The polar conductivity of air is defined as

$$
\sigma=n e b
$$

where $\mathrm{n}$ is the concentration of ions of mobility $\mathrm{b}$ and having an elementary charge e. In the absence of aerosol particles, polar conductivity is mainly due to the high-mobility small ions. However, in the presence of aerosol particles, small ions get attached to the aerosol particles. In the Simple Ion - Aerosol Model, the detailed reaction paths for the formation of individual cluster ions are not considered. The total number densities of positive and negative ions are assumed to be equal from the charge neutrality criterion. The equilibrium 
ion densities are computed from the equations of continuity where the effect of transport is neglected. These equations include aforementioned four types of loss processes. The two values of $\beta$ (for attachment of positive and negative ions with neutral aerosols) and $\alpha_{s}$ (for recombination of positive and negative ions with oppositely charged aerosols) are assumed to be equal.

The ion-aerosol interaction and involves primary ion pair production rate due to surface radioactivity and cosmic rays, the small ion densities $\left(\mathrm{N}_{ \pm}\right)$and the aerosol number density. For the model prediction of equilibrium ion density, it is necessary to use all the four loss processes of ions involved. The various recombination coefficients that enter into the model are: a) $\alpha_{i}$ - due to the loss of oppositely charged small ions, b) $\alpha_{a}$ - due to oppositely charged aerosol ions, c) $\alpha_{s}$ - is between small ions and aerosol ions and d) $\beta$ - due to attachment of small ions of similar polarities with aerosols.

The equations of continuity (i) for small ions in the absence of aerosols and in the presence of aerosols and (ii) the charged aerosols are given by:

$$
\begin{gathered}
\frac{d N_{0}}{d t}=q-\alpha_{i} N_{0}^{2} \\
\frac{d N_{ \pm}}{d t}=q-\alpha_{i} N_{ \pm}^{2}-\beta Z N_{ \pm}-\alpha_{S} A_{ \pm} N_{\mp} \\
\frac{d A_{ \pm}}{d t}=\beta Z N_{ \pm}-\alpha_{S} A_{ \pm} N_{\mp}-\alpha_{a} A_{ \pm}^{2}
\end{gathered}
$$

where $\mathrm{q}$ is the ion production rate due to radioactivity and cosmic rays, $\mathrm{N}_{0}$ is positive/negative ion density in the absence of aerosols, $N_{ \pm}$and $N_{\mp}$ are positive/negative ion densities in the presence of aerosols, $A_{ \pm}$is positively/negatively charged aerosol density, $\mathrm{Z}$ is neutral aerosol number density, $\beta$ is the aerosol-ion attachment coefficient, $\alpha_{i}$ is the ion-ion recombination coefficient, $\alpha_{s}$ is the charged aerosol-ion recombination coefficient, $\alpha_{\mathrm{a}}$ is the charged aerosol-aerosol recombination coefficient.

Under steady state conditions Eqs.(2), (3) and (4) reduce to:

$$
\begin{gathered}
q-\alpha_{i} N_{0}^{2}=0 \Rightarrow N_{0}=\left(\frac{q}{\alpha_{i}}\right)^{\frac{1}{2}} \\
q-\alpha_{i} N_{ \pm}^{2}-\beta Z N_{ \pm}-\alpha_{s} A_{ \pm} N_{\mp}=0 \\
\beta Z N_{ \pm}-\alpha_{s} A_{ \pm} N_{\mp}-\alpha_{a} A_{ \pm}^{2}=0
\end{gathered}
$$

Solving Eqs. (5), (6) and (7) for $N_{ \pm}$with $A_{ \pm}=N_{0}-N_{ \pm}$we get:

$$
N_{ \pm}=\frac{\left(\alpha_{a} N_{0}+\beta Z\right) \pm \sqrt{\left(\alpha_{a} N_{0}+\beta Z\right)^{2}-\left(\alpha_{a}-\alpha_{i}\right)\left(q+\alpha_{a} N_{0}^{2}\right)}}{\left(\alpha_{a}-\alpha_{i}\right)}
$$

Solving Eqs. (6) and (7) simultaneously, one can get: 


$$
\begin{aligned}
& \beta Z=\left(\frac{q-\alpha_{i} N_{ \pm}^{2}+\alpha_{a} A_{ \pm}^{2}}{2 N_{ \pm}}\right) \\
& \alpha_{s}=\left(\frac{q-\alpha_{i} N_{ \pm}^{2}+\alpha_{a} A_{ \pm}^{2}}{2 A_{ \pm} N_{\mp}}\right)
\end{aligned}
$$

The ion depletion $\Delta \mathrm{N}$, i.e., loss of molecular ions in presence of aerosols is given by $\Delta N=N_{0}-N_{ \pm}$. Further, this ion depletion is equal to the charged aerosol concentration, $\mathrm{A}_{ \pm}$. Hence, the fractional depletion, $\eta$ of small ions is used and computed as follows:

$$
\eta=\left(\frac{\Delta N}{N_{0}}\right)=\left(\frac{A_{ \pm}}{N_{0}}\right)
$$

Using Eqs. (11) and (5), we can write Eqs.(9) and (10), respectively, as

$$
\begin{gathered}
\beta Z=\left(\frac{N_{0} \eta\left[\alpha_{i}(2-\eta)+\alpha_{a} \eta\right]}{2(1-\eta)}\right) \\
\alpha_{s}=\left(\frac{\alpha_{i}(2-\eta)-\alpha_{a} \eta}{2(1-\eta)}\right)
\end{gathered}
$$

The conductivity of the atmosphere in the absence and presence of aerosols, respectively, are given by:

$$
\sigma_{0}=N_{0} e b_{ \pm} \& \sigma_{ \pm}=N_{ \pm} e b_{ \pm}
$$

where e is the charge of an electron, $b_{ \pm}$is the ionic mobility, $\sigma_{0}$ is the conductivity of the atmosphere in the absence of aerosols and $\sigma_{ \pm}$is the conductivity of the atmosphere in the presence of aerosols.

The ionic mobility $\left(b_{ \pm}\right)$is expressed in terms of the reduced mobility $\left(b_{0}\right)$ at normal temperature $\left(\mathrm{T}_{0}\right)$ and pressure $\left(\mathrm{P}_{0}\right)$, and the ambient temperature $(\mathrm{T})$ as well as pressure $(\mathrm{P})$ as follows:

$$
b_{ \pm}=\frac{b_{0} P_{0} T}{T_{0} P}
$$

The reduction in conductivity $(\Delta \sigma)$ due to depletion of small ions is given by:

$$
\Delta \sigma=\sigma_{0}-\sigma_{ \pm}
$$

The value of $\Delta \sigma$ is computed in terms of different model parameters from Eqs. (5)-(16) and by following the method of Gringel et al. (1978), we get:

$$
\Delta \sigma=\frac{\left[\left(2 \alpha_{i}-\alpha_{s}\right) \sigma_{0}+\beta Z e b_{ \pm}\right] \mp \sqrt{\left[\left(2 \alpha_{i}-\alpha_{s}\right) \sigma_{0}+\beta Z b_{ \pm}\right]^{2}+4\left(\alpha_{s}-\alpha_{i}\right) \sigma_{0} \beta Z e b_{ \pm}}}{2\left(\alpha_{i}-\alpha_{s}\right)}
$$




\subsection{Computation of conductivity}

Modeling the conductivity of the atmosphere requires a knowledge of recombination coefficients $\alpha_{i}, \alpha_{a}$ and $\alpha_{s}$. The value of $\alpha_{i}$ is estimated from the parametric formula (Smith and Adams, 1982; Datta et al., 1987). From the theoretical considerations, Hoppel (1985) has shown that, for singly charged aerosols, the relative magnitudes of $\alpha_{a}$ and $\alpha_{s}$ are such that $\alpha_{a}$ $\leq \alpha_{s} \leq \alpha_{i}$. Initially, with a suitable assumed value of $\alpha_{a}$, the value of $\eta$ is computed from Eq. (11), then the value of $\alpha_{s}$ is computed using Eq.(13). It is noted that, in this step, $\alpha_{s}$ becomes negative if the assumed value of $\alpha_{a}$ is unrealistically large. In the present computations $\alpha_{a}=$ $10^{-7} \mathrm{~cm}^{3} \mathrm{~s}^{-1}$ is found to be suitable. In presence of aerosols and depending on the magnitude of $\alpha_{i}, \alpha_{s}$ and $\beta Z$, the realistic values of $\Delta \mathrm{N}$ are obtained which lies between zero and $\mathrm{N}_{0}$, and satisfies the condition $0<N_{ \pm}<N_{0}$. The values of $\beta Z$ and $\alpha_{s}$ are obtained by solving Eqs.(9) and (12) simultaneously for $\beta Z$ and Eqs.(10) and (13) for $\alpha_{s}$ through iterative procedure until the difference between the values gets minimized. These values are substituted in Eq.(8) to obtain $\mathrm{N}_{ \pm}$. By knowing the experimental values of $\mathrm{q}, \mathrm{Z}, \mathrm{T}, \mathrm{P}$ and different attachment and recombination coefficients computed from the ion-aerosol balance equations, it is possible to estimate the values of $\mathrm{N}_{0}$ and $\mathrm{N}_{ \pm}$and hence, the values of $\sigma_{0}, \sigma_{ \pm}$and $\Delta \sigma_{ \pm}$.

\section{Results and discussion}

In an experimental programme at Pune (18032' N, 73051'E, $559 \mathrm{~m}$ above mean sea level), India measurements of radon and its progeny, aerosol number density and atmospheric conductivities are measured. Using the ionization rate from radioactivity, ambient aerosol density and meteorological parameters such as temperature, pressure and relative humidity, the small ion concentration and hence the conductivity of the atmosphere is estimated from an Ion-aerosol model. Model computed conductivity of the atmosphere is used to validate the measured conductivity from a Gerdien condenser setup. Nagaraja et al. (2006) have described the experimental method for the measurement of ground level atmospheric electrical conductivity near the earth's surface and its validation using a simple Ion-aerosol model. The present model work is an extension of the earlier work for the estimation of percent reduction in conductivity for assumed higher ambient aerosol levels, which may be the result of increased pollution due to vehicular exhaust, industrial effluents, anthropogenic activity etc. Thus, monitoring of ground level atmospheric conductivity can be useful in air pollution studies (Nagaraja Kamsali et al., 2009).

The diurnal variation of radon, its progeny, aerosols, small ion concentration and conductivity for a typical day are described. Even though, the observations differ quantitatively, they show similar trends of variations over a day. Variability in the data of any of these parameters can be associated with different meteorological conditions. Moreover, simultaneous measurements of the diurnal variations of radon, its progeny, aerosols, conductivity, dry and wet bulb temperature, and wind speed and direction at the same observatory confirm that the day chosen is in no way electrically or meteorologically abnormal from other fair weather days. Thus, the observations described below can be reasonably generalized for other fair weather days as well. The results of collocated measurements of the parameters such as concentrations of radon and its progeny, ionization rate, aerosols, electrical conductivity and meteorological parameters such as temperature, relative humidity are examined for a typical day and are taken as representative. 


\subsection{Variation of lonization rate due to radon and its progeny}

The diurnal variations of activities of radon and its progeny near the earth's surface are depicted in Fig. 3(a). The radon concentration varies from 2.1 to $23.0 \mathrm{~Bq} \mathrm{~m}^{-3}$ with a median of $6.8 \mathrm{~Bq} \mathrm{~m}^{-3}$ showing a significant diurnal variation, whereas values of radon progeny vary from 0.5 to $6.4 \mathrm{~Bq} \mathrm{~m}^{-3}$ with a median of $2.0 \mathrm{~Bq} \mathrm{~m}^{-3}$. It is seen from the figure that the concentrations are maxima during the early morning hours, generally between 0500 and $0700 \mathrm{hrs}$ of Indian Standard Time (IST). The concentration decreases after sunrise, attaining minima during the afternoon, 1000 to $1800 \mathrm{hrs}$ of IST. The variation of meteorological parameters such as temperature and relative humidity are shown in Fig. 3(b). It is observed that the concentration of radon and its progeny follow the trend of the relative humidity, in general. This is due to the fact that as temperature increases, the saturation vapour pressure increases so that the given air can take more water vapour. Consequently the relative humidity will decrease. The raise of temperature causes increased vertical mixing and raising of aerosols to the higher altitudes resulting in lower concentration of radon at the ground level (Hoppel et al., 1986). When the temperature decreases and relative humidity increases, the vertical mixing and raising of aerosols to the higher altitude reduces. As a consequence, the aerosol to which radon is attached, will be present at higher concentrations during night and in the early morning hours at ground level. This results in the increase of radon concentrations near the surface of the earth (Porstendörfer, 1994).

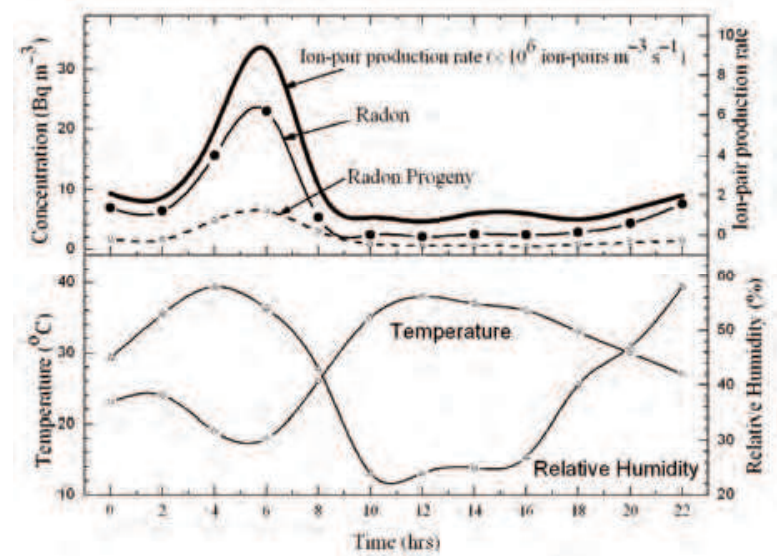

Fig. 3. Diurnal variation of a) radon, progeny and ion-pair production rate b) temperature and relative humidity

The ionization due to radioactivity also exhibits the diurnal variation as that of concentration of radon and its progeny and is shown in Fig. 3(a). At a height of $1 \mathrm{~m}$ above the surface ionization due to radioactive gases and their short-lived daughter products is predominantly caused by alpha particles. The rate of ionization due to radioactivity also exhibits the diurnal variation as that of concentration of radon and its progeny. The radon exhaled from the surface causes ionization of the atmosphere (Israel, 1970). It also shows a maximum in the early morning hours and a minimum in the afternoon (Dhanorkar and Kamra, 1994). The ion-pair production rate varies between 0.7 to 9.3 ion-pairs $\mathrm{cm}^{-3} \mathrm{~s}^{-1}$ with a mean of 2.4 ion-pairs $\mathrm{cm}^{-3} \mathrm{~s}^{-1}$. At night, ionization rates close to the ground are enhanced because of the accumulation of radioactive emanations from ground under temperature 
inversions and due to their lesser dispersion because of low winds (Hoppel et al., 1986). It also shows that the concentration of radon and its daughter products is low at noon when air is unstable and is highest during the night and early morning hours, when mixing is low. The radioactive emanations from the ground are trapped below inversions, and their accumulation causes an increase in ionization in the lower stable atmosphere during the nighttime. Large rates of ionization, produced due to these radioactive emanations in the presence of large aerosol concentration at night, produce large concentrations of ions of all categories. The accumulation of radioactive emanations will increase through the night until morning, when there are rapid changes in the stability of the atmosphere. In the morning, the vertical mixing caused due to increased eddy diffusivity will dilute the concentration of aerosols and radioactive emanations close to the ground. This may explain the occurrence of large concentrations at nighttime as compared to daytime (Dhanorkar and Kamra, 1993).

\subsection{Variation of aerosol concentration and its size distribution}

Figure 4(a) represents two hourly values of the aerosol concentration obtained for each of the eight size categories in the range of 13 to $750 \mathrm{~nm}$. It shows a diurnal variation with the concentration showing a minimum during the early morning around 0600 hours IST and an increasing trend towards noon-hours. Early in the morning, due to anthropogenic activity and also due to the onset of convection resulting from the increase in atmospheric temperature, aerosols are pushed into the atmosphere resulting in an increased aerosol concentration (Israelsson et al., 1994; Sasikumar et al., 1995).
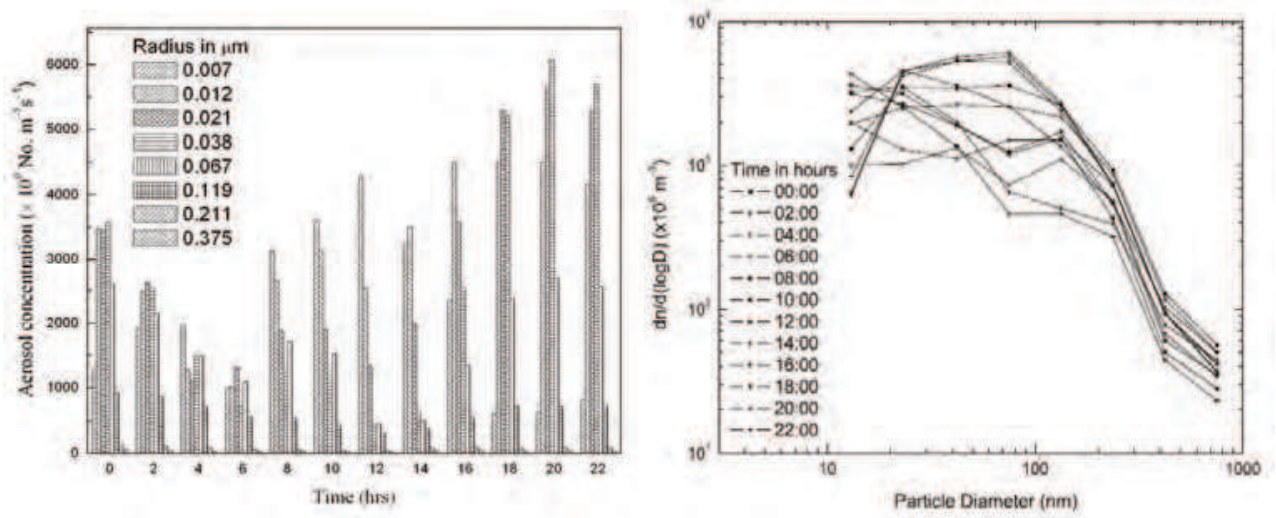

Fig. 4. Variation of aerosols a) over a day and b) its size distribution

The size distribution of aerosols is plotted in Fig. 4(b) are generally bimodal with their maxima at 75 and $23 \mathrm{~nm}$ during night (1800 to $0400 \mathrm{hrs}$ ). After 0400 hour with slight shift in maxima in the accumulation mode towards the higher size. During daytime, particularly in the afternoon, the shift in maxima in the accumulation mode to a higher diameter of $133 \mathrm{~nm}$ is distinct and the maxima in the nucleation mode seem to shift to smaller diameter. As a result of increase in the concentration of small particles, the size distribution curves during daytime are mostly open ended at the small particle side (Murugavel and Kamra, 1999). The magnitude of the peaks varies with time. 


\subsection{Variation of small ion concentration}

The diurnal variation of estimated small ion concentration for a period of one week along with its mean values is shown in Fig. 5(a). Relatively a large day-to-day difference in the concentrations of ions that may arise from the difference in the accumulations of radioactive emanations and aerosol particles due to varying degrees of the lower atmospheric stability and/or due to varying intensities of advection. It is observed that the concentration show maxima in the early morning around $0600 \mathrm{hrs}$ IST, it decreases after sunrise, and attains minimum in the afternoon. Radioactive emanations from ground are trapped below inversions, and their accumulations cause an increase in ionization and consequently increase in concentration in the lower atmosphere during the nighttime (Hoppel et al., 1986). Increased vertical mixing caused by increase in temperature and rising of aerosols to the higher altitudes results in the lower value of ionization rate at the ground level (Nagaraja et al., 2006). The concentration varies between 436 and 1663 ions $\mathrm{cm}^{-3}$ with a mean of 734 ions $\mathrm{cm}^{-3}$.
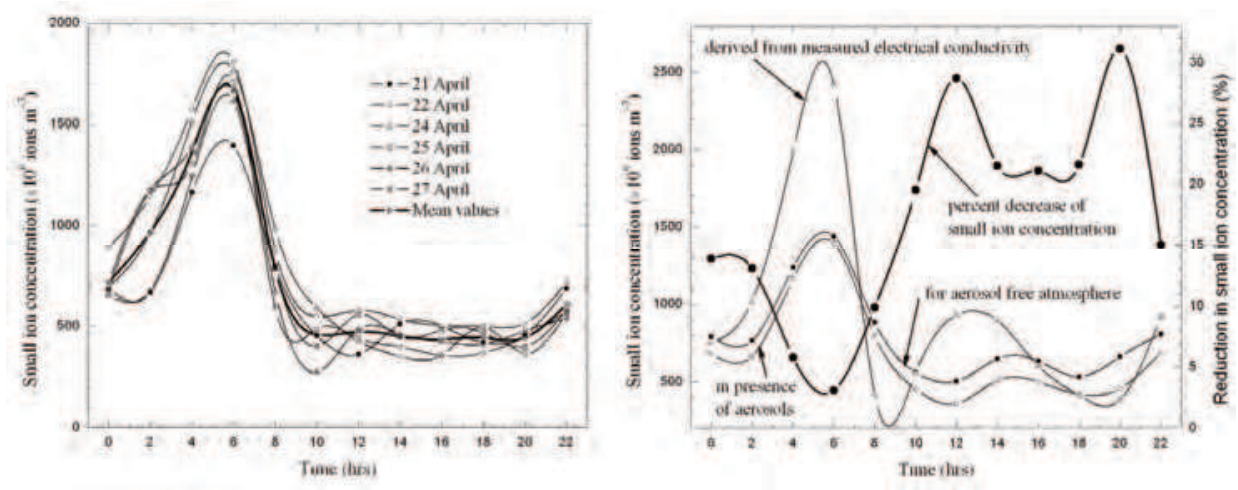

Fig. 5. Variation of a) small ion concentration b) small ion concentration in presence and absence of aerosols

The estimated small ion concentration shows a positive correlation with ionization rate due to surface radioactivity near to the Earth's surface. There is a correlation of $98.4 \%$ and suggests that the theoretical approach is best fitted and the correlation obtained indicates the correctness of ion-aerosol interaction considerations (Nagaraja Kamsali et al., 2009). Also shown in the figure is the estimated concentration of ions in the absence and in presence of aerosols using Eqs. (5) and (8), respectively. There is a fair agreement between theoretically estimated small ion concentration and experimentally derived values during daytime. However, there is a considerable difference during the morning hours. This difference is due to the large variability in measured conductivity. The percentage decrease in small ion concentration due to presence of aerosols is also shown in Fig. 5(b). The decrease is more during the noon-time when the aerosol concentration is high and less in the early morning when aerosol concentrations are minima. The maximum reduction in the estimated small ion concentration observed at around $2000 \mathrm{hrs}$ coincides with the observed maximum concentration in aerosols. It is also seen that the existence of aerosols reduces the concentration and the percent reduction of small ion concentration is found to be minimum during early morning hours and starts increasing after sun rise and remains more or less 
same in the afternoon till sunset and reduces after words. This clearly shows that aerosols will have a control over the small ion concentration and hence the electrical structure of the atmosphere. A good correlation of $87.3 \%$ observed between the small ion concentration against derived values of small ion concentration from the measured electrical conductivity and suggests that the ion-aerosol balance equations considered are good enough to explain the interactions and are comparable with the experimental measurements of Dhanorkar and Kamra (1993).

\subsection{Variation of conductivity}

The diurnal behaviour of conductivity is found to be different at sites having different levels of natural radioactivity. Diurnal variations of experimental positive and negative ion conductivities for a continental station are shown in Fig. 6(a). The diurnal variation of conductivity of both polarities indicates that the pattern is representative of the regions. The positive and negative conductivities are approximately equal and their diurnal variations are generally mirror images to each other. It is observed that the conductivity of both polarities show maxima in the early morning hours between 0400 and $0700 \mathrm{hrs}$ of IST, it decreases after sunrise, and attains minimum in the afternoon. This is due to the fact that the raise in temperature causes increased vertical mixing and rising of aerosols to the higher altitudes, which results in the lower value of ionization rate, and hence conductivity at the ground level (Dhanorkar et al., 1989; Nagaraja et al., 2006). The positive conductivity varies between 0.3 to $1.8 \times 10^{-14} \Omega^{-1} \mathrm{~m}^{-1}$ with a median of $0.8 \times 10^{-14} \Omega^{-1} \mathrm{~m}^{-1}$ and the negative conductivity varies between 0.2 to $2.0 \times 10^{-14} \Omega^{-1} \mathrm{~m}^{-1}$ with a median of $0.7 \times 10^{-14} \Omega^{-1} \mathrm{~m}^{-1}$.

During nighttime the atmosphere is relatively calm with low winds and little convective motion. The radon exhaled from the soil therefore accumulates near the ground and leads to increased ionization and higher conductivity. After sunrise, due to human activity and also due to the onset of convection resulting from the increase in atmospheric temperature, aerosols are pushed into the atmosphere. This causes a conversion of small ions, that are responsible for conductivity, into large ions through attachment, and an increase in the destruction of small ions through recombination with large ions of opposite polarity. The onset of circulation also removes radon from near the ground to higher altitude regions. These factors contribute to the observed reduction in conductivity in the afternoon (Subbaramu and Vohra, 1969). In the evening, with decreasing ground temperatures and also the anthropogenic activity, the aerosols that had been pushed to higher altitudes begin to settle down, and a greater fraction of small ions is lost through attachment. Conductivity therefore again starts raising after sunset. Finally, at nightfall, the aerosols settle down, and the conductivity recovers its normal night time high values. Since the major contribution to ionization at the surface comes from surface radioactivity and radon/thoron emanating from the soil, one would expect the diurnal variation pattern of conductivity to reflect that of the radon concentration near the surface. Radon and its short-lived daughters are understood to show a diurnal variation in concentration with a maximum early in the morning and a minimum in the afternoon (Nagaraja et al., 2003a). This is ascribed to the variations in the vertical mixing of air near the surface, which is controlled by atmospheric stability. As convection builds up with solar heating of the ground, radioactive gases are also transported upward, where they add to the ambient ionization. This leads to a reduction in the concentration of these gases, and consequently of ionization, near the surface (Nagaraja et al., 2003b). Therefore one should expect higher conductivities during 
the period of atmospheric stability, with the values decreasing with the onset of turbulence (Sasikumar et al., 1995; Prasad et al., 2005). Wilkening and Romero (1981) reported the values of ionization rate, positive conductivity and negative conductivity, respectively, as $1.5 \mathrm{~cm}^{-3} \mathrm{~s}^{-1}, 1.4 \times 10^{-14} \Omega^{-1} \mathrm{~m}^{-1}$ and $1.4 \times 10^{-14} \Omega^{-1} \mathrm{~m}^{-1}$, for free atmosphere. These are of the same order as our measurements reported in this paper. The conductivity values presented here are of the same order of Dhanorkar and Kamra (1993). The total conductivity is the algebraic sum of the experimentally measured values of polar conductivities i.e., positive and negative conductivity. The variation of total conductivity is shown in Fig. 6(b). It varies between 0.6 to $3.9 \times 10^{-14} \Omega^{-1} \mathrm{~m}^{-1}$ with a median of $1.5 \times 10^{-14} \Omega^{-1} \mathrm{~m}^{-1}$. The increase of conductivity in the early morning hours is mainly because of the ionization produced by radioactive substances present in the atmosphere. The correlation coefficient between the ionization rate, obtained from the radioactivity, and the measured electrical conductivity is found to be $98 \%$ for a typical day and shows that the conductivity at the ground is mainly because of the ionization due to radioactivity near the surface.

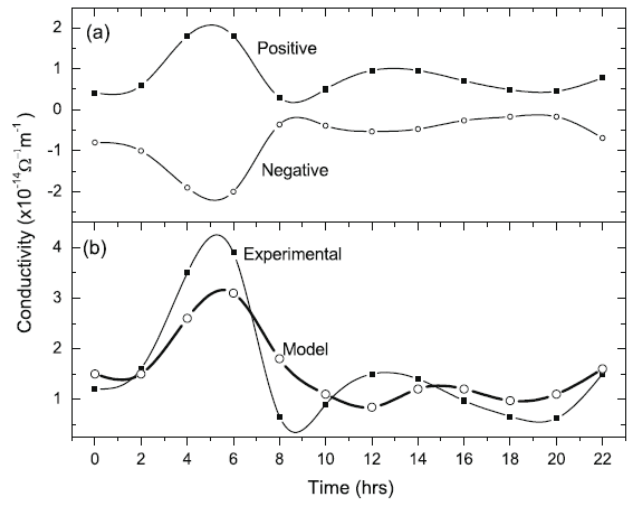

Fig. 6. Variation of a) positive and negative conductivity b) experimental and model conductivity

The experimental conductivity fluctuations in Fig. 6 is due to the similar variations in $\mathrm{q}$ which in turn is affected by the variations in meteorological parameters such as temperature, humidity, wind speed etc. The model of this study has reproduced well this trend of the diurnal variation in conductivity. It is seen that there is no exact one to one match between the experimental and model conductivities at certain points. However, there is a correlation coefficient of more than $90 \%$ between experimental and model derived conductivity values, which is an indication of correctness of the model results. In this study, the standard deviation in the measured ionization rates and aerosol concentration are both less than $10 \%$. It is observed that the variations in the model conductivity values for the $10 \%$ variations in $\mathrm{q}$ and/or $\mathrm{Z}$ show variations of about $7 \%$ or less. It is evident that the simple Ion-aerosol model of this study has adequately reproduced the experimental conductivity.

\subsection{Variation of conductivity under enhanced aerosols conditions}

The conductivity of air is entirely due to small ions and depends upon the number of small ions present in the atmosphere. The conductivity decreases if the small ion concentration 
reduces. The small ion concentration is altered by the presence of aerosols due to attachment with aerosols, apart from the usual loss due to mutual recombination between the ions of opposite polarity. Hence, the conductivity alters due to the presence of aerosols in the atmosphere. Variation of conductivity due to enhanced (from the background) aerosols is plotted in Fig. 7(a). Three curves indicate that the conductivity decreases as the aerosol concentration increases. Fig. 7(b) shows the percent reduction in conductivity due to the presence of aerosols derived from the model for normal condition. In the early morning hours the concentration of aerosols is less and the conductivity is more (Houghton, 1985). Convective currents in the morning carry aerosol particles up from ground surface and the aerosols change the high mobility small ions into low mobility large ions. Thus the conductivity decreases after sunrise (Dhanorkar et al., 1989). As the day advances the aerosol concentration increases due to anthropogenic activities and conductivity decreases. The percent decrease in conductivity shows a diurnal variation with a minimum in the early morning hours when the aerosol concentration is minimum and reaches a maximum $(30-32$ $\%)$ in the afternoon when aerosol concentration also shows maximum. Due to pollution the concentration of aerosols increases and leads to decrease in conductivity of the atmosphere near the surface (Retalis et al., 1991; Dhanorkar and Kamra, 1993). Thus the measurement of atmospheric conductivity can be used as an index of pollution in the atmosphere. Also estimated from the Ion-Aerosol model is the reduction in small ion concentration and hence the conductivity of the atmosphere for varying levels of aerosols and as seen in Fig. 7(b). The results reveal that, for an increase of background aerosols by three-fold the percent reduction in conductivity is $7 \%$, and for an increase of aerosols by six-fold the reduction in conductivity is $10 \%$ from the measured ambient aerosol level.
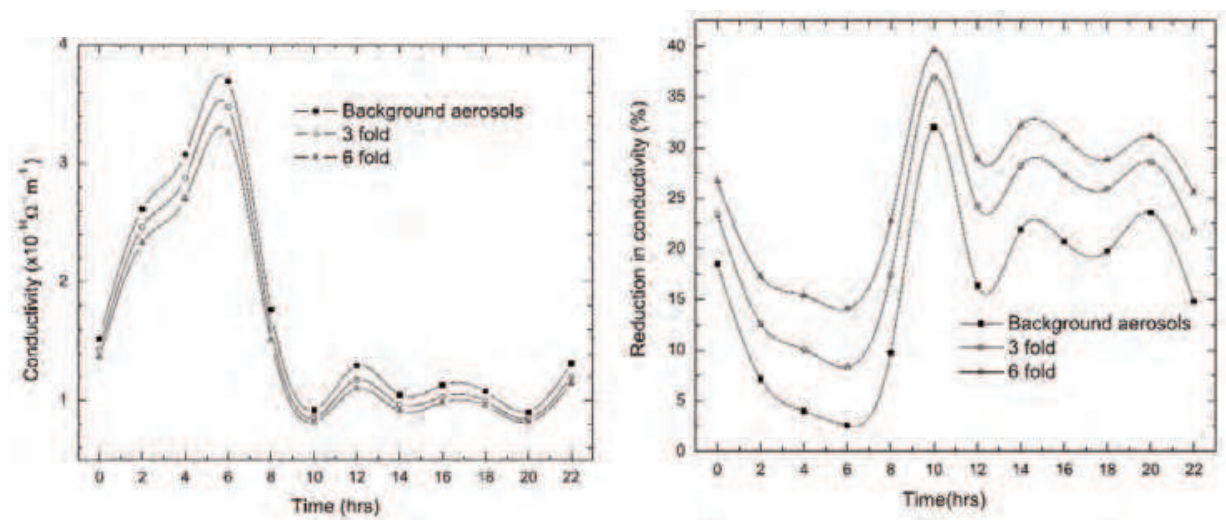

Fig. 7. Variation of conductivity a) in presence of aerosols and enhanced aerosols conditions b) percent decrease in conductivity for enhanced aerosol conditions

The diurnal, weekly and annual patterns of atmospheric electrical conductivity seem to be well correlated with the local aerosol air pollution patterns. The long-term decreasing trend seems to be affected by the air pollution build-up over metropolitan areas. Convective 
currents in the morning carry aerosol particles up into atmosphere; change the high mobility small ions into low mobility large ions. Thus the conductivity decreases after sunrise. As the day advances the aerosol concentration increases due to anthropogenic activities and conductivity decreases. The percent decrease in conductivity shows a diurnal variation with a minimum in the early morning hours when the aerosol concentration is minimum and reaches a maximum $32 \%$ for a typical day in the afternoon when aerosols also show maximum for background aerosols. Due to pollution the concentration of aerosols increases and leads to decrease in conductivity of the atmosphere near the surface. This gives an idea that the measurement of conductivity can be used as an index of pollution measurement. The result also reveals that, for an increase of aerosols by 3 -fold the percent reduction in conductivity is $7 \%$, and for an increase of aerosols by 6 -fold the reduction in conductivity is $10 \%$ from the pollution free atmosphere.

\section{Summary}

The electrical conductivity of the atmosphere is mainly due to the radioactive substances in the earth's crust and their emanation near the surface. The radiations emitted by the radioactive substances ionize the atmospheric air and leads to conductivity. The conductivity gets altered because of the existence of aerosols in the atmosphere. A simple Ion aerosol model has been developed to deduce the conductivity theoretically by using ionization rate, aerosol concentration, and different attachment and recombination coefficients for the loss of small ions as input to the model. The model agrees well with the experimentally measured conductivity. In addition to this, it is seen from the model that the percent reduction in conductivity is $7 \%$ and $10 \%$ for an increase of ambient background aerosols by three-fold and six-fold, respectively.

\section{Acknowledgements}

The work was proposed under the financial support from the Department of Science and Technology (DST), Government of India. The authors (Nagaraja and Prasad) are thankful to the funding agency, and to Dr. A. K. Kamra and Dr. S. D. Pawar, Indian Institute of Tropical Meteorology, Pune, India for the fabrication of the Gerdien condenser and permitting us to carry out the experiments in Pune.

\section{References}

Chalmers, J.A. (1967). Atmospheric Electricity. Pergamon press, Oxford, London.

Cobb, W.E. (1973). Oceanic aerosol levels deduced from measurements of the electrical conductivity of the atmosphere, Journal of Atmospheric Science, 30, 101-106.

Cobb, W.E. \& Wells, H.J. (1970). The electrical conductivity of oceanic air and its correlation to global atmospheric pollution. Journal of Atmospheric Science, 27, 814-819.

Datta, J., Chakravarty, S.C. \& Mitra, A.P. (1987). A model for the cosmic ray produced ionization in the middle atmosphere. Indian Journal of Radio and Space Physics, 16, 257-266. 
Dhanorkar, S. \& Kamra, A. K. (1992). Relation between electrical conductivity and small ions in the presence of intermediate and large ions in the atmosphere, Journal of Geophysical Research, 97, 20345-20360.

Dhanorkar, S. \& Kamra, A. K. (1993). Diurnal and seasonal variations of the small-, intermediate-, and large-ion concentrations and their contributions to polar conductivity, Journal of Geophysical Research, 98, 14895-14908.

Dhanorkar, S. \& Kamra, A. K. (1994). Diurnal variation of ionization rate close to ground, Journal of Geophysical Research, 99, 18523-18526.

Dhanorkar, S. \& Kamra, A. K. (1997). Calculation of electrical conductivity from ion-aerosol balance equations. Journal of Geophysical Research, 102, 30147-30159.

Dhanorkar, S., Deshpande, C. G. \& Kamra, A. K. (1989). Observations of some atmospheric electrical parameters in the surface layer, Atmospheric Environment, 23, 839-841.

Gringel, W., Kaselan, K.H. \& Muhleisen, R. (1978) Recombination rates of small ions and their attachment to aerosol particles. Pure and Applied Geophysics, 116, 1101-1113.

Hoppel, W.A. (1985). Ion-aerosol attachment coefficients, ion depletion, and the charge distribution on aerosols. Journal of Geophysical Research, 90, 5917-5923.

Hoppel, W.A., Anderson, R.V. \& Willet, J.C. Atmospheric electricity in the planetary boundary layer, In: The earth's electrical environment, National Academy Press, Washington, D.C., USA, pp. 149-165, 1986.

Houghton, H.G. Physical Meteorology. MIT Publications, Cambridge, Massachusetts, England, 1-452, 1985.

Israel, H., Atmospheric Electricity, Vol.1, Israel Program for Scientific Translations, Jerusalem, 1-317, 1970.

Israelsson, S., Knudsen, E. \& Anisimov, S.V. (1994). Vertical profiles of electrical conductivity in the lowermost part of the turbulent boundary layer over flat ground. Journal of Atmospheric and Terrestrial Physics, 56, 1545-1550.

Kamra, A.K. \& Deshpande, C.G. (1995). Possible secular change and land-to ocean extension of air pollution from measurements of electrical conductivity over the Bay of Bengal. Journal of Geophysical Research, 100, 7105-7110, 1995.

Liu, B.Y.H. E. \& Pui, D.Y.H. (1975). On the performance of the electrical aerosol analyzer. Journal of Aerosol Science, 6, 249-264.

Mani, A. \& Huddar, B.B. (1972). Studies of the surface aerosols and their effect on atmospheric electric parameters. Pure and Applied Geophysics, 100, 154-166.

Misaki, M. \& Takeuti, T. (1970). The extension of air pollution from land over ocean as related in the atmospheric electrical conductivity. Journal of Meteorological Society of Japan, 48, 263-269, 1970.

Misaki, M. (1964). Mobility spectrums of large ions in the New Mexico semidesert. Journal of Geophysical Research, 69, 3309-3318.

Morita, Y., Ishikawa, H. \& Kanazawa, J. (1972). Atmospheric electrical conductivity measurements in the Pacific Ocean, exploring the background level of global pollution. Journal of Meteorological Society of Japan, 497-500, 1972.

Murugavel, P. \& Kamra, A.K. (1999). Changes in the concentration and size-distribution of the sub-micron particles associated with the sea-and land-breezes at a coastal station. Current Science, 76, 994-997. 
Nagaraja, K., Prasad, B. S. N., Madhava, M. S. \& Paramesh, L., (2003a). Concentration of radon and its progeny near the surface of the earth at a continental station Pune (18 N, 74 E), Indian Journal of Pure and Applied Physics, 41, 562-569.

Nagaraja K., Prasad, B.S.N., Madhava, M.S., Chandrashekara, M.S., Paramesh, L., Sannappa, J., Pawar, S.D., Murugavel, P. \& Kamra, A.K. (2003b). Radon and its short-lived progeny: Variations near the ground. Radiation Measurement, 36, 413-417.

Nagaraja K., Prasad, B.S.N., Srinivas, N. \& Madhava, M.S. (2006). Electrical conductivity near the Earth's surface: Ion-aerosol model. Journal of Meteorological Society of Japan, 68, 757-768.

Nagaraja Kamsali., B.S.N. Prasad. \& Jayati Datta. (2009). Atmospheric electrical conductivity measurements and modeling for application to air pollution studies. Advances in Space Research, 44, 1067-1078.

Porstendörfer, J. (1994). Properties and behaviour of radon and thoron and their decay products in the air, Journal of Aerosol Science, 25, 219-263.

Prasad, B.S.N., Nagaraja, K., Chandrashekara, M.S., Paramesh, L. \& Madhava, M.S. (2005). Diurnal and seasonal variations of radioactivity and electrical conductivity near the surface for a continental location Mysore, India. Atmospheric Research, 76, 65-77.

Prasad, B.S.N., Srinivas, N. \& Chandramma, S. (1991). A simplified ion-aerosol model for balloon measurements of ion conductivity and aerosol concentration. Indian Journal of Pure and Applied Physics, 20, 304-306.

Raghavayya, M. (1998). Modification of Kusnetz method for estimation of radon progeny concentration in air, Radiation Protection and Environment, 21, 127-132.

Retalis, D., Pitta, A. \& Psallidas, P. (1991). The conductivity of the air and other electrical parameters in relation to meteorological elements and air pollution in Athens, Meteorological Atmospheric Physics, 46, 197-204.

Rosen, J.M. \& Hofmann, D.J. (1981). Balloon-borne measurements of electrical conductivity, mobility and the recombination coefficients. Journal of Geophysical Research, 86, 7406-7410.

Sasikumar, V., Sampath, S., Muralidas, S. \& Vijaykumar, K. (1995). Atmospheric electrical conductivity variations over different environments. Geophysics Journal International, 122, 89-96.

Smith, D. \& Adams, N.G. (1982). Ionic recombination in the stratosphere. Geophysical Research Letter, 9, 1085-1087.

Srinivas, N. \& Prasad, B.S.N. (1993). Seasonal and latitudinal variations of stratospheric small ion density and conductivity. Indian Journal of Pure and Applied Physics, 22, 122-127.

Srinivas, N. \& Prasad, B.S.N. (1996). A detailed model study of stratospheric small ion density and conductivity. Indian Journal of Pure and Applied Physics, 25, 255-262.

Srinivas, N., Prasad, B.S.N. \& Nagaraja, K. (2001). An ion-aerosol model study for the stratospheric conductivity under enhanced aerosol condition. Indian Journal of Pure and Applied Physics, 30, 31-35.

Subbaramu, M.C. \& Vohra, K.G. (1969). Investigations on radioactive equilibrium in the lower atmosphere between radon and its short-lived decay products. Tellus, 21, 395-403. 
Wilkening, M. \& Romero, V. (1981). ${ }^{222 R n}$ and atmospheric electrical parameters in the Carlsbad caverns. Journal of Geophysical Research, 86, 9911-9916. 


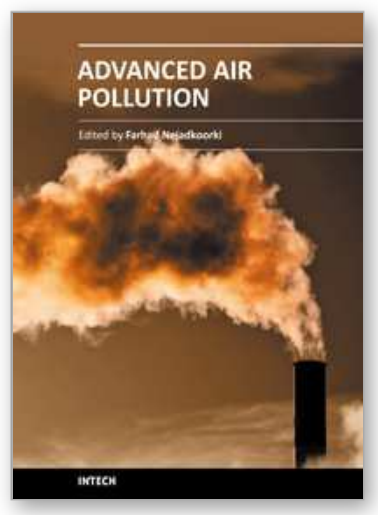

\author{
Advanced Air Pollution \\ Edited by Dr. Farhad Nejadkoorki
}

ISBN 978-953-307-511-2

Hard cover, 584 pages

Publisher InTech

Published online 17, August, 2011

Published in print edition August, 2011

Leading air quality professionals describe different aspects of air pollution. The book presents information on four broad areas of interest in the air pollution field; the air pollution monitoring; air quality modeling; the GIS techniques to manage air quality; the new approaches to manage air quality. This book fulfills the need on the latest concepts of air pollution science and provides comprehensive information on all relevant components relating to air pollution issues in urban areas and industries. The book is suitable for a variety of scientists who wish to follow application of the theory in practice in air pollution. Known for its broad case studies, the book emphasizes an insightful of the connection between sources and control of air pollution, rather than being a simple manual on the subject.

\title{
How to reference
}

In order to correctly reference this scholarly work, feel free to copy and paste the following:

Nagaraja Kamsali, B.S.N. Prasad and Jayati Datta (2011). The Electrical Conductivity as an Index of Air Pollution in the Atmosphere, Advanced Air Pollution, Dr. Farhad Nejadkoorki (Ed.), ISBN: 978-953-307-511-2, InTech, Available from: http://www.intechopen.com/books/advanced-air-pollution/the-electrical-conductivity-asan-index-of-air-pollution-in-the-atmosphere

\section{INTECH}

open science | open minds

\section{InTech Europe}

University Campus STeP Ri Slavka Krautzeka 83/A 51000 Rijeka, Croatia Phone: +385 (51) 770447 Fax: +385 (51) 686166 www.intechopen.com

\section{InTech China}

Unit 405, Office Block, Hotel Equatorial Shanghai No.65, Yan An Road (West), Shanghai, 200040, China 中国上海市延安西路65号上海国际贵都大饭店办公楼405单元 Phone: +86-21-62489820

Fax: +86-21-62489821 
(C) 2011 The Author(s). Licensee IntechOpen. This chapter is distributed under the terms of the Creative Commons Attribution-NonCommercialShareAlike-3.0 License, which permits use, distribution and reproduction for non-commercial purposes, provided the original is properly cited and derivative works building on this content are distributed under the same license. 